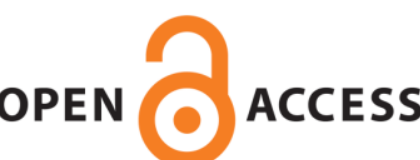

UWS Academic Portal

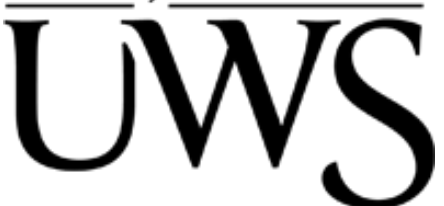

\title{
Different soccer stud configurations effect on running and cutting movements
}

Sun, Dong; Gu, Yaodong; Mei, Qichang; Baker, Julien S.

Published in:

International Journal of Biomedical Engineering and Technology

DOI:

10.1504/IJBET.2017.083814

E-pub ahead of print: 24/04/2017

Document Version

Peer reviewed version

Link to publication on the UWS Academic Portal

Citation for published version (APA):

Sun, D., Gu, Y., Mei, Q., \& Baker, J. S. (2017). Different soccer stud configurations effect on running and cutting movements. International Journal of Biomedical Engineering and Technology, 24(1), 19-32.

https://doi.org/10.1504/IJBET.2017.083814

\section{General rights}

Copyright and moral rights for the publications made accessible in the UWS Academic Portal are retained by the authors and/or other copyright owners and it is a condition of accessing publications that users recognise and abide by the legal requirements associated with these rights.

Take down policy

If you believe that this document breaches copyright please contact pure@uws.ac.uk providing details, and we will remove access to the work immediately and investigate your claim. 
3 Abstract: The purpose of this study was to testing for difference in performance and

4 injury risks between three different outsole configuration soccer shoes on natural turf.

5 A total of 14 experienced soccer players participated in the tests. Participants were asked to complete tasks of straight-ahead running and $45^{\circ}$ left sidestep cutting

7 respectively at the speed of $5.0 \pm 0.2 \mathrm{~m} / \mathrm{s}$ on natural turf. They selected soccer shoes with

8 firm ground design (FG), artificial ground design (AG) and turf cleats (TF) randomly.

9 During $45^{\circ}$ cut, FG showed significantly smaller peak knee flexion and greater 10 abduction angles than TF. FG showed significant greater Peak horizontal ground 11 reaction force (GRF) and average required traction ratio compared with AG and TF. 12 This study also found that FG showed the highest peak pressure and force-time integral 13 in the heel (H) and medial forefoot (MFF). FG may offer a performance benefit on 14 artificial turf compared to AG and TF on natural turf. However, increased knee valgus angle and decreased knee flexion angle of FG may increase knee loading and risk of anterior cruciate ligament (ACL) injury. Higher vertical average loading rate and excessive plantar pressure of FG may also resulted in calluses observed in plantar skin, forefoot pain or even metatarsal stress fracture. In summary, FG would enhance athletic performance on natural turf, but also may undertake higher risks of non-contact injuries compared with AG and TF.

21 Keywords: stud configurations; running; cutting; natural turf.

\section{Introduction}

24 Soccer is one of the world's most popular sports and is enjoyed by many through playing at all levels. The biomechanical factors relevant to success in the game of soccer are those which relate to the technical performance of skills, to the equipment used and to the causative mechanisms of injury (Lees and Nolan, 1998). Soccer is a highly competitive contact sport, changes of speed and direction occur every 4-6 s in soccer, such as cutting and turning movements. During changes of direction the pivot leg initially decelerates the body, torso or pelvis then rotates away from the pivot leg towards the new direction (Sterzing et al., 2009). The ability to perform fast cutting maneuvers is essential in soccer. These cutting maneuvers are characterized by 
33 substantial changes in speed, thus requiring large horizontal impulses exerted by the

34 feet on the surface (Luo and Stefanyshyn, 2011). These movements should be finished in a short time, and the quality of these movements not only influence athletic performance but also affect potential non-contact injuries of lower limbs (Driscoll et al., 2012; Smith et al., 2004).

During athletic movements, shoes are considered to play a vital role in the transmission of forces from surface to athlete, soccer players greatly rely on the design of their footwear to enable optimum performance (Hennig 2011). The soccer shoes provides grip to the playing surface, protects the foot, and facilitates ball control. To ensure a player can successfully perform the movement with minimal slipping, sufficient traction at the shoe-surface interface is required (Kent et al., 2015; Lake 2000).

44 Previous study has highlighted traction between shoes and surface as a leading cause 45 of ankle and knee injuries in soccer (Nigg and Segesser, 1988; Torg and Quedenfeld, 46 1971). Non-contact sports injuries often occurs in knee, ankle and foot, current studies 47 had shown that these injuries closely related to the design of soccer shoes and turf 48 conditions (Kaila 2007). Previous studies had shown that stud type, stud length, and 49 stud geometry on various surface conditions would influence running performance 50 (Muller et al., 2009). In the process of sidestep cutting movement, longer studs would 51 provide more grip to improve athletic performance, but higher traction may lead to knee 52 abduction moment significantly increased, which will increase the risk of ACL injury. 53 Some studies had suggested an increased risk of ACL injury with decreased knee 54 flexion angles and increased knee abduction angles during movements involving rapid 55 changes of direction (Boden et al., 2000; Malinzak et al., 2001; Hewett et al., 2005). 56 During running, some plantar regions could bear double or triple body weight, the 57 additional pressure of these specific plantar regions may lead to potential risks of 58 plantar fasciitis and metatarsal stress fractures (Morio et al., 2009). Pressure insoles was used to measure specific plantar anatomical regions of 21 professional soccer players, 60 through the process of straight-ahead running and sidestep cutting, it was found that 61 during sidestep cutting, plantar pressure of medial forefoot and lateral forefoot were 62 significantly higher than straight-ahead running (Eils et al., 2004). It has been reported 63 that artificial turf, including both infilled and non-infilled, contribute to 1.73 ACL 64 injuries per 1000 athletes compared to 1.24 ACL injuries per 1000 athletes on natural 
65 turf (Dragoo et al., 2013). On the contrary, a recent three-year prospective study of 465

66 collegiate soccer players showed significantly lower injury incidence (46.6\%) on

67 artificial turf compared to natural turf (53.4\%) (Meyers 2010). In addition, these studies

68 had failed to find a significant difference in injury incidence between artificial turf and 69 natural turf in soccer.

70 Several studies had revealed the effects of different soccer stud configurations on

71 biomechanical characteristics on natural turf. Therefore, the purpose of this study was

72 to investigate the lower limb kinematics and kinetics with different studded soccer

73 shoes on natural turf during straight-ahead running and $45^{\circ}$ left sidestep cutting

74 movements. This could lead to a more comprehensive knowledge of player-surface

75 interaction and provide further understanding of the mechanism of athletic performance 76 and injury risk.

77

782 Materials and methods

792.1 Participants

80 The study was approved by the ethical committee of Ningbo University. Before the

81 experiments, the subjects were informed of the objectives, requirements and

82 experimental procedures. All gave informed written consent to participate in the study.

83 Sixteen male soccer players (mean \pm SD: age, $19.7 \pm 1.2 \mathrm{y}$; height, $1.73 \pm 0.04 \mathrm{~m}$ and

84 body mass, $66.7 \pm 4.4 \mathrm{~kg}$; soccer experience, $12.1 \pm 2.2$ y) from university soccer team

85 were recruited for this study, and only right-leg dominant players were included in the

86 study. A minimum of 2 years' experience with natural turf, free of major injuries to the

87 lower extremities for the past 6 months.

882.2 Equipment

89 Different studded soccer shoes were sponsored by ANTA Sports Science Laboratory, 90 stud design were firm ground design (FG) with 11 studs, artificial ground design (AG) 91 with 23 studs, turf cleats shoes (TF) with 71 short cleats covering the entire sole (Table

92 1). Natural turf in this study was approved for national competition, a separate piece of 93 natural turf was securely mounted on top of the force platform, the pile height was $9460 \mathrm{~mm}$ and weight of the natural turf $\left(25 \mathrm{~kg} \cdot \mathrm{m}^{-2}\right)$ ensured stability. 


\begin{tabular}{lccc}
\hline & & & \\
\hline Studs design & Firm Ground (FG) & Artificial Ground (AG) & Turf Cleats (TF) \\
Number of studs & 11 & 23 & 71 \\
Length of studs & $12-16 \mathrm{~mm}$ & $8-12 \mathrm{~mm}$ & $3-7 \mathrm{~mm}$ \\
\hline
\end{tabular}

98 The 8-camera Vicon motion analysis system (Oxford Metrics Ltd., Oxford, UK) was

99 used to capture participant's lower limb kinematics at a frequency of $200 \mathrm{~Hz}$. A standard 100 reflective marker set was pasted to different positions of the lower limb and used to 101 define joint centers and axes of rotation. Subjects were required to wear tight-fitting 102 pants and 16 reflective markers (diameter: $14 \mathrm{~mm}$ ) were attached with adhesive on the 103 left and right lower limbs, respectively. The marker locations included: anterior104 superior iliac spine, posterior-superior iliac spine, lateral mid-thigh, lateral knee, lateral 105 mid-shank, lateral malleolus, second metatarsal head and calcaneus. The marked points 106 on the second metatarsal head and calcaneus were placed on the corresponding 107 anatomical. The in-shoe plantar pressure measurement system (Novel Pedar System, 108 Germany) was used to measure the pressure and force exerted on the insole pressure 109 sensors, which were divided into seven anatomical parts, including heel $(\mathrm{H})$, medial 110 foot (MF), medial forefoot (MFF), central forefoot (CFF), lateral forefoot (LFF), big 111 toes (BT) and other toes (OT) (Figure 1). All the insoles for the experiment had been 112 regulated with a pressure pump before each participant's experiment. All subjects ran 113 with the right foot step onto the force plate (Kistler, Switzerland), which was fixed in 114 6-meter away from the starting line and utilized to collect the ground reaction force 115 (GRF) at a frequency of $1000 \mathrm{~Hz}$. Velocity of straight-ahead running $\left(0^{\circ}\right)$ and cutting $116\left(45^{\circ}\right)$ movements were measured using Brower timing lights (Brower Timing System, 117 Draper, UT, USA). To ensure accurate kinetic data collection, a separate piece of natural 118 turf was cut to $60 \mathrm{~cm} \times 90 \mathrm{~cm}$ to fit the dimension of force platform. 


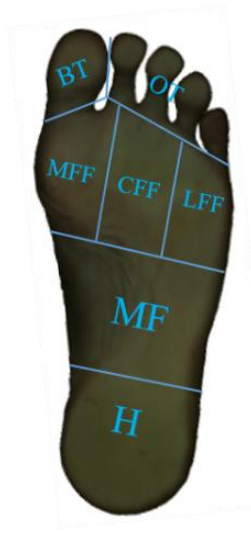

\subsection{Data acquisition}

122 All running tests and experiments were conducted at the Sports Biomechanics

123 Laboratory of Ningbo University. The design of experiment protocol is given in figure

124 2. A 3-minutes warm-up before experiment for every subject, shoe order and 125 movements were randomized across subjects. Both straight-ahead running and $45^{\circ}$ cut 126 were performed at the speed of $5.0 \pm 0.2 \mathrm{~m} / \mathrm{s}$, subjects were given one minute rests 127 between trials and five minutes rests between shoe and movement conditions. If the 128 subject did not land with right foot on the force platform, trails were discarded and the 129 subject was asked to repeat the movement. Subjects were asked to land near the center 130 of force platform to ensure accurate force collection. Subjects were instructed to heel 131 landing of cutting movement, and landing pattern of straight-ahead running make no 132 demands. Six trails that were deemed acceptable were collected in each condition. 133 Kinematics and kinetics of each shoe and movement were synchronously measured.

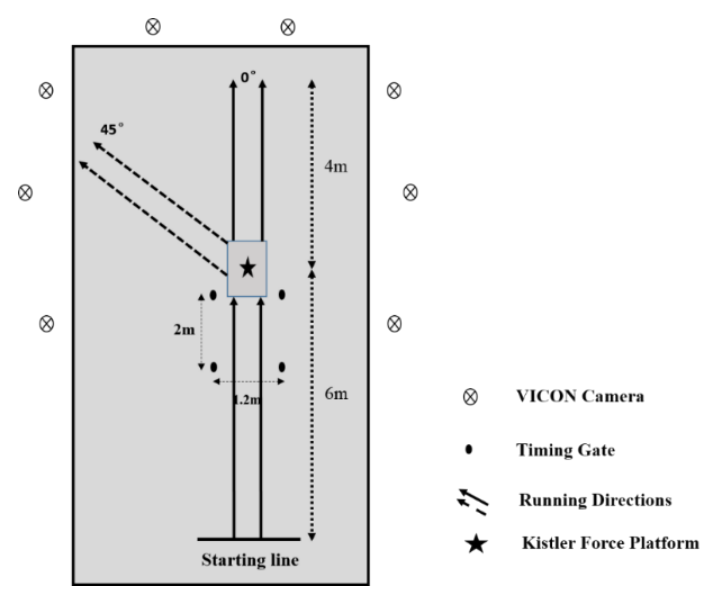

Figure 2 Design of experiment protocol

137 The SPSS 17.0 software (SPSS Inc., Chicago, IL, USA) was used for statistical 
138 analysis. The Post Hoc Multiple Comparisons and LSD (least significance difference)

139 of ANOVA (analysis of variance) were taken for kinematic parameters, variables of 140 ground reaction force, peak pressure and force time integral of the straight-ahead

141 running and $45^{\circ}$ left sidestep cutting .The significance level was set at 0.05 .

142

1433 Result

\subsection{Kinematic results}

145 Three dimensional kinematics of knee and ankle joints were analyzed during stance 146 phase of $45^{\circ}$ cut (Table 2 and 3). Kinematics of knee and ankle joints varies due to 147 different stud configurations. In sagittal plane, peak knee flexion angle of firm ground 148 design (FG) and artificial ground design $(\mathrm{AG})$ were significantly smaller $(\mathrm{P}<0.001)$ 149 than turf cleats (TF). Also knee flexion-extension range of motion (ROM) varied due 150 to shoe conditions with FG generating smaller values $(\mathrm{p}=0.013<0.05)$ than TF (Table

151 2). In frontal plane, peak knee abduction angles of FG was significantly greater than $152 \mathrm{AG}(\mathrm{p}<0.001)$ and TF $(\mathrm{p}<0.001)$. Peak ankle dorsiflexion angle showed no significant 153 difference between stud conditions, but ankle dorsiflexion-plantarflexion range of 154 motion $(\mathrm{ROM})$ showed a significant difference $(\mathrm{p}<0.001)$ between FG and TF (Table $1553)$.

Table 2. Summary of the knee kinematic variable of cutting movement, mean $(S D)$

\begin{tabular}{lccc}
\hline & \multicolumn{3}{c}{$45^{\circ}$ left sidestep cutting } \\
\cline { 2 - 4 } & FG & AG & TF \\
\hline Peak flexion angle $\left(^{\circ}\right)$ & $38.8 \pm 5.2^{\#}$ & $39.4 \pm 5.9^{*}$ & $42.9 \pm 6.1$ \\
Flexion-Extension $\left.\operatorname{ROM}^{\circ}\right)$ & $27.6 \pm 3.3^{\#}$ & $28.7 \pm 4.3$ & $29.8 \pm 3.7$ \\
Peak abduction angle $\left(^{\circ}\right)$ & $7.8 \pm 2.6^{\&}, \#$ & $-6.4 \pm 3.1$ & $-6.3 \pm 3.4$ \\
Abduction-Adduction $\mathrm{ROM}^{\circ}\left(^{\circ}\right)$ & $4.4 \pm 1.5$ & $3.2 \pm 1.3$ & $3.2 \pm 1.1$ \\
Peak external rotation angle $\left(^{\circ}\right)$ & $-8.7 \pm 2.9$ & $-8.7 \pm 2.3$ & $-8.6 \pm 3.5$ \\
Internal-External rotation $\mathrm{ROM}^{\circ}\left(^{\circ}\right)$ & $14.3 \pm 4.2$ & $14.1 \pm 4.4$ & $14.5 \pm 3.8$ \\
\hline
\end{tabular}

157 Notes: ROM represent range of motion. \& indicates significant difference between FG and AG, $158 \mathrm{p}<0.05$; \# indicates significant difference between FG and TF, $\mathrm{p}<0.05$; * indicates significant difference between $\mathrm{AG}$ and $\mathrm{TF}, \mathrm{p}<0.05$. 
Table 3. Summary of the ankle kinematic variable of cutting movement, mean (SD).

\begin{tabular}{lccc}
\hline & \multicolumn{3}{c}{$45^{\circ}$ left sidestep cutting } \\
\cline { 2 - 4 } & FG & AG & TF \\
\hline Peak dorsiflexion angle $\left(^{\circ}\right)$ & $28.8 \pm 3.1$ & $28.9 \pm 3.6$ & $29.2 \pm 3.4$ \\
Dorsiflexion-Plantarflexion ROM $\left(^{\circ}\right)$ & $51.7 \pm 7.4^{\#}$ & $52.9 \pm 6.7$ & $54.3 \pm 7.1$ \\
Peak inversion angle $\left(^{\circ}\right)$ & $3.4 \pm 2.8$ & $3.5 \pm 2.9$ & $3.6 \pm 3.1$ \\
Inversion-Eversion ROM $\left(^{\circ}\right)$ & $8.3 \pm 5.3$ & $8.9 \pm 4.7$ & $8.7 \pm 5.1$ \\
Peak internal rotation angle $\left(^{\circ}\right)$ & $4.5 \pm 2.1$ & $4.5 \pm 2.5$ & $4.4 \pm 2.6$ \\
Internal-External rotation $\mathrm{ROM}\left({ }^{\circ}\right)$ & $13.7 \pm 4.3$ & $13.9 \pm 3.8$ & $13.8 \pm 4.4$ \\
\hline
\end{tabular}

163 Note: \# indicates significant difference between FG and TF, $\mathrm{p}<0.05$.

1643.2 Kinetic results

165 Subjects were instructed wearing FG, AG and TF shoes to complete the tasks of 166 straight running and $45^{\circ}$ sidestep cutting respectively, with right foot land near the center 167 of Kistler force platform to obtain ground reaction force (GRF). GRF of each subject 168 were normalized to body weight (BW), peak vertical ground reaction force (vGRF) 169 showed no significant different between different stud configurations. Horizontal 170 ground reaction forces (hGRF) were calculated in this study, peak hGRF of FG was 171 significantly higher than AG $(\mathrm{p}<0.001)$ and TF $(\mathrm{p}<0.001)$ during stance phase of $45^{\circ}$ 172 cut, separately. Vertical average loading rate (VALR) is the first peak GRF divided by 173 the corresponding time (Force/Time). VALR of FG ( $p<0.001)$ and AG $(\mathrm{p}=0.003<0.05)$

174 were significantly higher than $\mathrm{TF}$ (Table 4), respectively. 
Table 4. Variables of ground reaction force $(n=14)$, mean (SD)

\begin{tabular}{lcccccc}
\hline & \multicolumn{3}{c}{ straight running $\left(0^{\circ}\right)$} & \multicolumn{3}{c}{$45^{\circ}$ sidestep cutting } \\
& FG & AG & TF & FG & AG & TF \\
\hline Peak vertical ground & 2.53 & 2.52 & 2.52 & 2.71 & 2.69 & 2.70 \\
reaction force (BW) & $(0.12)$ & $(0.14)$ & $(0.17)$ & $(0.23)$ & $(0.19)$ & $(0.25)$ \\
Peak horizontal ground & 2.63 & 2.62 & 2.62 & 5.26 & 5.14 & 5.12 \\
reaction force (BW) & $(0.22)$ & $(0.19)$ & $(0.24)$ & $(0.48)^{\& \#}$ & $(0.47)$ & $(0.51)$ \\
Vertical average & & & & 94.5 & 94.4 & 90.3 \\
loading rate (BW/s) & - & - & - & $(7.1)^{\&}$ & $(5.8)^{*}$ & $(6.7)$ \\
& & & & 0.207 & 0.208 & 0.208 \\
Time of contact (s) & 0.165 & 0.166 & 0.165 & 0.208 \\
& $(0.012)$ & $(0.009)$ & $(0.010)$ & $(0.012)$ & $(0.011)$ & $(0.014)$ \\
\hline
\end{tabular}

185

Notes: "-" Not applicable for the given movement; BW, body weight;

$$
\& \text { indicates significant difference between FG and AG, } \mathrm{p}<0.05 \text {; }
$$

$$
\begin{aligned}
& \text { \# indicates significant difference between } \mathrm{FG} \text { and TF, } \mathrm{p}<0.05 \text {; } \\
& \text { * indicates significant difference between } \mathrm{AG} \text { and } \mathrm{TF}, \mathrm{p}<0.05 \text {. }
\end{aligned}
$$

The required (or utilized) traction was quantified using the time dependent traction ratio, dividing the horizontal by the vertical component of the ground reaction force. Horizontal ground reaction force (hGRF) was the resultant force in horizontal plane. Defining $\delta$ as required traction ratio between shoe and surface of cutting movement, the equation of traction ratio presents as follows:

$$
\delta=h G R F / v G R F
$$

The traction ratio shows large variability at initial and end of stance phase during cutting movement. Therefore, the average traction value was calculated in the interval where the traction ratio is rather constant, starting at $10 \%$ of stance phase and ending when the vertical ground reaction force dropped under body weight towards the end of stance phase (Clercq et al., 2014), as shown in the gray area of figure 3. The average required traction ratio of $\mathrm{FG}, \mathrm{AG}$ and $\mathrm{TF}$ shoes were $2.18 \pm 0.12,1.98 \pm 0.09$ and $1.96 \pm 0.13$. FG showed significant greater average required traction ratio compared with AG $(\mathrm{p}<0.001)$ and $\mathrm{TF}(\mathrm{p}<0.001)$ during stance phase of $45^{\circ}$ left sidestep cutting. 


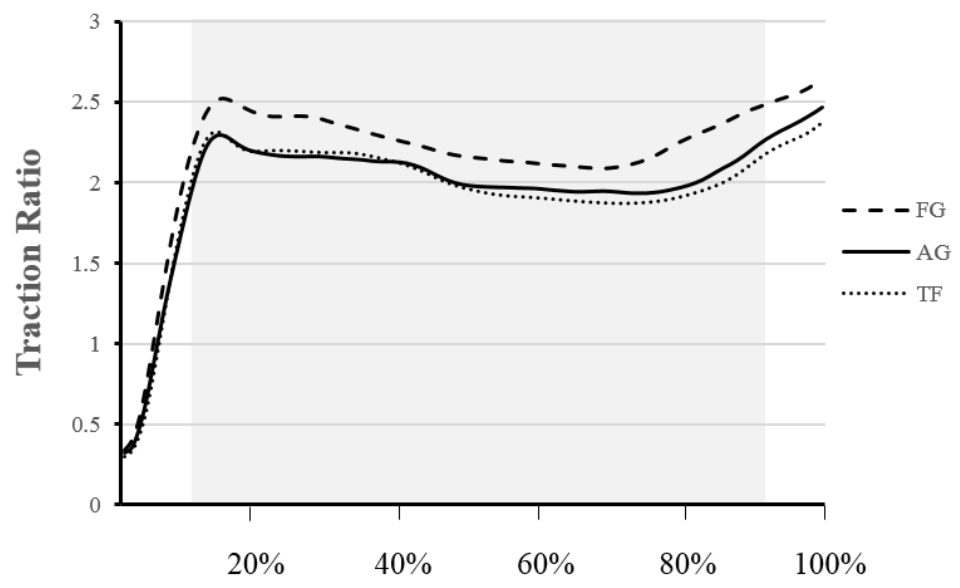

Stance Phase (\%)

205 Figure 3 Traction ratio of three stud conditions during stance phase of $45^{\circ}$ cut.

206 Note: The grey area indicates the interval during which the mean traction was calculated.

207 Peak pressure and force time integral were collected at different anatomical regions 208 for the analysis of impact on different outsole hardness. Due to different foot strike 209 patterns of straight-ahead running, the comparative analysis of different shoe type were 210 only performed on the forefoot and toes. During stance phase of straight-ahead running, 211 peak pressure in medial forefoot (MFF) of FG were significantly higher $(\mathrm{P}=0.008<0.05)$ 212 than TF, and force-time integral in MFF of FG was also showed significantly higher $213(\mathrm{p}=0.006<0.05)$ than TF (Figure 4).
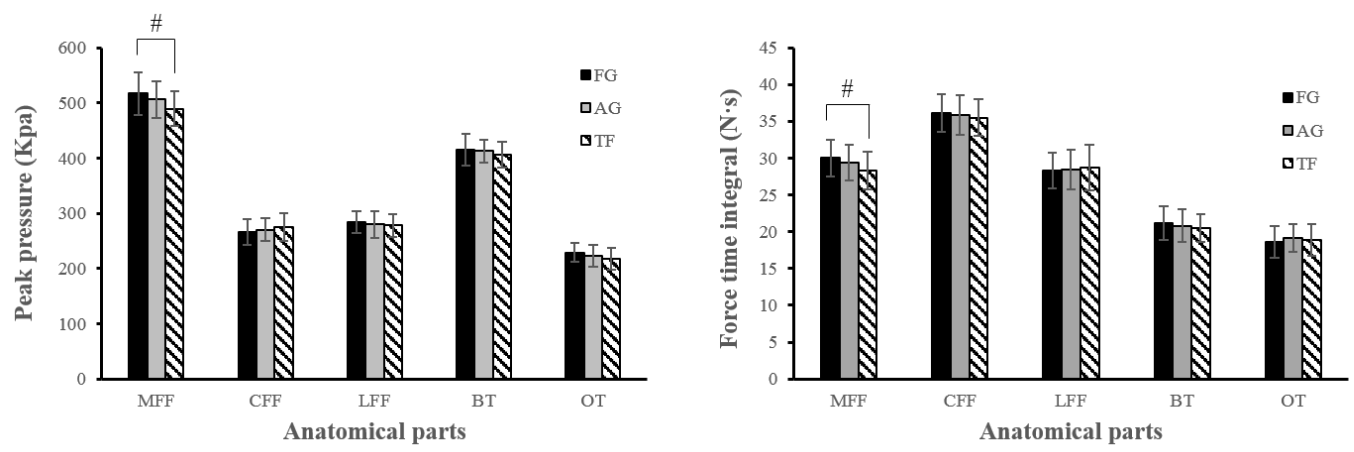

215 Figure 4 Peak pressure and force-time integral of three stud conditions in straight216 ahead running.

217 Note: \# indicates significant difference between FG and TF, $\mathrm{p}<0.05$.

218 During stance phase of $45^{\circ}$ left sidestep cutting, plantar pressure showed significant 219 difference between different stud conditions in the heel (H) and medial forefoot (MFF) regions. Peak pressure of TF in the heel region was significantly smaller than AG 
$221(\mathrm{P}=0.004<0.05)$ and $\mathrm{FG}(\mathrm{p}<0.001)$, and force-time integral of TF was also significantly

222 smaller than $\mathrm{AG}(\mathrm{p}=0.006<0.05)$ and FG $(\mathrm{p}=0.003<0.05)$. In the medial forefoot region,

223 peak pressure of FG was significantly greater $(\mathrm{p}=0.009<0.05)$ than $\mathrm{TF}$, and force-time

224 integral of FG was also higher $(\mathrm{p}<0.001)$ than TF (see Figure 5).

225

226

227

228

229

230

231

232

233

234

235

236

237

238

239

240

241

242

243
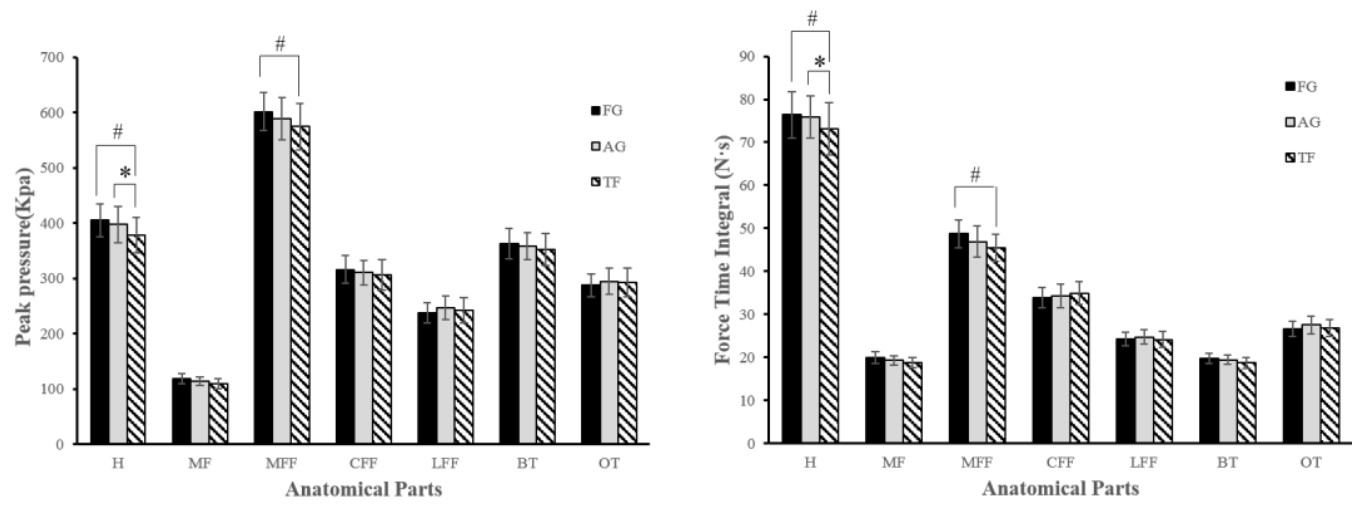

Figure 5 Peak pressure and force-time integral of three stud conditions in $45^{\circ}$ cut.

Notes: \# indicates significant difference between FG and TF, $\mathrm{p}<0.05$;

* indicates significant difference between AG and TF, $\mathrm{p}<0.05$.

\section{Discussion}

Experienced soccer players executed straight-ahead running and $45^{\circ}$ left sidestep cutting movements, testing for difference in performance and non-contact injury risks with three soccer stud configurations on natural turf.

It was hypothesized that the natural turf studs would produce a greater peak vertical GRF and its loading rate compared to artificial turf studs and turf cleats during cutting movements. The results showed no significant differences in peak vertical GRF between stud type conditions of cutting movement. Gehring et al. (2007) found no significant differences in peak vertical GRF during a cross-over cutting performed by soccer players wearing traditional round studs and bladed studs, also Griffin et al. (2000) found that both soccer shoe stud conditions and outsole material showed no significant difference in peak vertical GRF. But peak horizontal GRF varies between different stud configurations during cutting movement in this study, FG produce a greater peak horizontal GRF compared with AG and TF. The utilized traction ratio of cutting movement in this study was dividing the horizontal by the vertical component of the ground reaction force (Luo and Stefanyshyn, 2011; Clercq et al., 2014), higher horizontal GRF of FG may produce more traction between shoe and surface. Sufficient 
247 traction between footwear and turf is extremely important for sport performance. It 248 allows an athlete to cutting or turning sharply without skidding (Schrier et al., 2014).

249 The grey area of figure 4 indicates the interval during which the mean traction ratio was 250 calculated, mean utilized traction ratio of FG was significantly higher than AG and TF.

251 It was found that cleat or stud shape and length as well as their arrangement across the 252 outsole will modify the interaction of the shoe with the ground and produce different 253 traction properties (Muller 2010). And the present study found as cleat length increased 254 from $0 \%$ to $50 \%$ to $100 \%$ of its original length, straight accelerating and cutting 255 performance improved with longer cleats (Muller 2009). Luo identified the more 256 traction available, the more an athlete can lean into the surface and direct the GRF 257 toward the favored direction, resulting in a greater acceleration (Luo and Stefanyshyn, 258 2011). However, Muller evaluate the traction characteristics of four different stud 259 configurations on third-generation artificial turf, results showed mechanical traction 260 ratio of soft ground design was the highest, but it displayed the worst results in the 261 performance and in the perception testing among the four traction conditions (Muller 262 2010). In general, faster cutting should result in increased utilized traction.

263 During stance phase of straight-ahead running and $45^{\circ}$ cut, peak pressure and force264 time integral showed significant differences, mainly in the MFF. FG showed the highest 265 peak pressure and force-time integral in MFF of both movements in this study. 266 Compared with turf cleats shoes, natural stud design with longer stud may elevate 267 plantar pressure of some areas on both third-generation turf and natural turf. Impulse is 268 defined as force and time integral, Time of contact in straight-ahead running and $45^{\circ}$ 269 cutting showed no significant different between three stud conditions. The force 270 produced an accumulative effect during a certain period of time for plantar regions,

271 higher force-time integral could provide more impulse. Higher pressure also could 272 provide more vertical propulsive force to achieve better athletic performance (Bergstra 273 et al., 2014). In summary, speculated that FG may do more help to increasing athletic 274 performance in both running and cutting movements.

275 Dynamic changes of direction have been determined as a risk factor for non-contact 276 injuries in soccer, and these injuries normally occurred in ankle joint, knee joint and 277 some plantar regions (Fong et al., 2007). During stance phase of cutting, FG and AG 278 showed significant smaller knee flexion angles compared with TF. Decreased knee 
279 flexion angles reduce the ability of lower extremity to absorb compressive loads placed

280 on the knee, putting it at risk for injury, increased knee flexion may reduce impact and

281 load on knee joint (Boden et al., 2000; Derrick 2002), speculated smaller knee load of

282 TF during cutting movement. Boden et al. (2000) also found that while the mechanism

283 of frontal plane loading during landing and cutting tasks was different, increased knee

284 valgus load during cutting was considered a risk factor for non-contact ACL injury.

285 Peak knee abduction angles of FG was higher than TF, some studies had suggested an

286 increased risk of ACL injury with decreased knee flexion angles and increased knee

287 abduction angles during movements involving rapid changes of direction (McLean et

288 al., 2004). Ankle kinematics did not display significant differences in peak dorsiflexion

289 angle between stud conditions, but dorsiflexion-plantarflexion ROM was significantly

290 greater for the TF compared with FG. Decreased ROM may lead to decreased

291 absorption capacity of the ankle and increased injury potential. Malliaras et al. (2006)

292 stated that the decreased dorsiflexion-plantarflexion ROM may reduce impact

293 attenuation capacity of the ankle and therefore increase the knee joint loads and anterior

294 tibia translation and strain on the ACL.

295 This study showed that FG was associated with the greatest peak horizontal GRF and

296 VALR compared with TF. GRF and VALR have both been reported as risk factors

297 associated with lower extremity injuries. Increased horizontal GRF make greater higher

298 loads on the lateral ankle ligaments during $45^{\circ}$ cut, leading to more potential risk to

299 lateral ankle sprains (Jenkyn and Nicol, 2001). Higher VALR may increase the impact

300 force to lower limbs and may lead to potential risk of tibia stress fracture and plantar

301 fasciitis (Mei et al., 2015). Peak pressure and force-time integral in the heel (H) region

302 of FG were also significantly higher than TF (Figure 5), which would also increase the

303 potential risk factors of tibia stress fractures and plantar fasciitis (Lieberman et al.,

304 2010). Speculated TF may provide more impact absorption compared with FG. Higher

305 utilized traction could produce more grip which allows athletes to cutting and turning

306 rapidly without skidding. However, the shortcoming of higher utilized traction of FG

307 has also been proposed to be associated with athlete injury. It has been proposed that

308 higher utilized traction might lead to risk of slip resistance and foot fixation which

309 might increase the load of lower limbs. Slip resistance and foot fixation are two

310 potential factors of non-contact injuries. Foot fixation has been related to the knee 
311 injuries (D’Ambrosia 1985; Torg 1982). In the direction phase of cutting movement, to

312 prevent slipping injuries an adequate level of traction ratio is necessary, speculated that

313 traction ratio should be as low as possible and able to provide adequate slip resistance.

314 FG showed significant greater peak pressure and force-time integral compared with

315 TF in the MFF, also greater than AG but showed no significant difference. The medial

316 forefoot (first and second metatarsal) of FG bears more loading compared with other

317 stud conditions during stance phase of cutting movement. Though increased plantar

318 pressure is correlated with faster running speed, excessive pressure and an accumulative

319 effect in a small area may result in calluses observed in plantar skin, forefoot pain or

320 even metatarsal stress fracture (Grouios 2004; Keijsers et al., 2013). Which is consistent

321 with studies that higher forefoot pressure of bladed cleat design could concluded to be

322 substantially more harmful than round cleat design (Bentley et al., 2011). During stance

323 phase of $45^{\circ}$ cut, increased plantar pressure of FG elevate the compressive load on the

324 knee joint which may be connect with increased risk of ACL injury, in addition to 325 decreased knee flexion angle and increased knee abduction angle.

\section{Conclusion}

328 During stance phase of $45^{\circ}$ cut, decreased knee flexion angles and increased knee 329 abduction angles of firm ground design (FG) may increase knee loading and risk of 330 anterior cruciate ligament (ACL) injury. Higher utilized traction of FG could produce 331 more grip which allows athletes to cutting rapidly without skidding. However, higher 332 utilized traction might lead to risk of slip resistance and foot fixation which might 333 increase the load of lower limbs. Elevated plantar pressure of FG may improve 334 impulsive force to enhance athletic performance, therefore excessive pressure and an 335 accumulative effect in a small area may result in calluses observed in plantar skin, 336 forefoot pain or even metatarsal stress fracture. In summary, FG may enhance athletic 337 performance on natural turf, but also may undertake higher risks of non-contact injuries 338 compared with artificial ground design (AG) and turf cleats (TF).

340 Acknowledgement: The study sponsored by National Natural Science Foundation of 341 China (81301600), K.C.Wong Magna Fund in Ningbo University, and Zhejiang 342 Xinmiao Innovation Talents Scheme (2015R405094). 
Bentley, J. A., Ramanathan, A. K., Arnold, G. P., Wang, W., \& Abboud, R. J. (2011). Harmful cleats of football boots: 'A biomechanical evaluation', Foot and Ankle Surgery, Vol. 17, No. 3, pp. 140-144.

Bergstra, S. A., Kluitenberg, B., Dekker, R., Bredeweg, S. W., Postema, K., Van den Heuvel, E. R., ... \& Sobhani, S. (2014). 'Running with a minimalist shoe increases plantar pressure in the forefoot region of healthy female runners', Journal of Science and Medicine in Sport, Vol. 18, No. 4, pp. 463-468.

Boden, B. P., Feagin Jr, J. A., \& Garrett Jr, W. E. (2000). 'Mechanisms of anterior cruciate ligament injury', Orthopedics, Vol. 23, No. 6, pp. 573-578. D'Ambrosia, R. D. (1985). 'Orthotic devices in running injuries', Clinics in sports medicine, Vol. 4, No. 4, pp. 611-618.

De Clercq, D., Debuyck, G., Gerlo, J., Rambour, S., Segers, V., \& Van Caekenberghe, I. (2014). 'Cutting performance wearing different studded soccer shoes on dry and wet artificial turf', Footwear Science, Vol. 6, No. 2, pp. 81-87.

Derrick, T. R., Dereu, D. A. R. R. I. N., \& McLean, S. P. (2002). 'Impacts and kinematic adjustments during an exhaustive run', Medicine and science in sports and exercise, Vol. 34, No. 6, pp. 998-1002.

Dragoo, J. L., Braun, H. J., \& Harris, A. H. (2013). 'The effect of playing surface on the incidence of ACL injuries in National Collegiate Athletic Association American Football', The Knee, Vol. 20, No. 3, pp. 191-195.

Driscoll, H., Kirk, B., Koerger, H., \& Haake, S. (2012). 'Influence of outsole design on centre of rotation during turning movements', Procedia Engineering, Vol. 34, pp. 301306.

Eils, E., Streyl, M., Linnenbecker, S., Thorwesten, L., Völker, K., \& Rosenbaum, D. (2004). 'Characteristic plantar pressure distribution patterns during soccer-specific movements', The American Journal of Sports Medicine, Vol. 32, No. 1, pp. 140-145. systematic review on ankle injury and ankle sprain in sports', Sports medicine, Vol. 37, 373 No. 1, pp. 73-94.

374 Gehring, D., Rott, F., Stapelfeldt, B., \& Gollhofer, A. (2007). 'Effect of soccer shoe 375 cleats on knee joint loads', International journal of sports medicine, Vol. 28, No. 12, pp. 1030-1034. 
377 Griffin, L. Y., Agel, J., Albohm, M. J., Arendt, E. A., Dick, R. W., Garrett, W. E., ... \& 378 Johnson, R. J. (2000). 'Noncontact anterior cruciate ligament injuries: risk factors and 379 prevention strategies', Journal of the American Academy of Orthopaedic Surgeons, Vol. 380 8, No. 3, pp. 141-150.

381 Grouios, G. (2004). 'Corns and calluses in athletes' feet: a cause for concern', The 382 Foot, Vol. 14, No. 4, pp. 175-184.

383 Hennig, E. M. (2011). 'The influence of soccer shoe design on player performance and 384 injuries', Research in Sports Medicine, Vol. 19, No. 3, pp. 186-201.

385 Hewett, T. E., Myer, G. D., Ford, K. R., Heidt, R. S., Colosimo, A. J., McLean, S. G., ... $386 \&$ Succop, P. (2005). 'Biomechanical measures of neuromuscular control and valgus 387 loading of the knee predict anterior cruciate ligament injury risk in female athletes a 388 prospective study', The American journal of sports medicine, Vol. 33, No. 4, pp. 492389501.

390 Jenkyn, T. R., \& Nicol, A. C. (2001). 'Protective ankle muscle activation strategies 391 during quick cutting movement in humans', In 25th annual meeting of American 392 Society of Biomechanics, San Diego, CA.

393 Kaila, R. (2007). 'Influence of modern studded and bladed soccer boots and sidestep 394 cutting on knee loading during match play conditions', The American journal of sports medicine, Vol. 35, No. 9, pp. 1528-1536.

396 Kent, R., Forman, J. L., Crandall, J., \& Lessley, D. (2015). 'The mechanical interactions 397 between an American football cleat and playing surfaces in-situ at loads and rates 398 generated by elite athletes: a comparison of playing surfaces', Sports biomechanics, Vol. 399 14, No. 1, pp. 1-17.

400 Keijsers, N. L. W., Stolwijk, N. M., Louwerens, J. W. K., \& Duysens, J. (2013). 401 'Classification of forefoot pain based on plantar pressure measurements', Clinical 402 biomechanics, Vol. 28, No. 3, pp. 350-356.

403 Lake, M. J. (2000). 'Determining the protective function of sports footwear', 404 Ergonomics, Vol. 43, No. 10, pp. 1610-1621.

405 Lees, A., \& Nolan, L. (1998). 'The biomechanics of soccer: a review', Journal of sports 406 sciences, Vol. 16, No. 3, pp. 211-234.

407 Lieberman, D. E., Venkadesan, M., Werbel, W. A., Daoud, A. I., D’Andrea, S., Davis, 408 I. S., ... \& Pitsiladis, Y. (2010). Foot strike patterns and collision forces in habitually 409 barefoot versus shod runners. Nature, Vol. 463, No. 7280, pp. 531-535.

410 Luo, G., \& Stefanyshyn, D. (2011). 'Identification of critical traction values for 
411 maximum athletic performance', Footwear Science, Vol. 3, No. 3, pp. 127-138.

412 Malinzak, R. A., Colby, S. M., Kirkendall, D. T., Yu, B., \& Garrett, W. E. (2001). 'A

413 comparison of knee joint motion patterns between men and women in selected athletic

414 tasks', Clinical Biomechanics, Vol. 16, No. 5, pp. 438-445.

415 Malliaras, P., Cook, J. L., \& Kent, P. (2006). 'Reduced ankle dorsiflexion range may 416 increase the risk of patellar tendon injury among volleyball players', Journal of science 417 and medicine in sport, Vol. 9, No. 4, pp. 304-309.

418 McLean, S. G., Lipfert, S. W., \& van den Bogert, A. J. (2004). 'Effect of gender and 419 defensive opponent on the biomechanics of sidestep cutting', Medicine and Science in 420 Sports and Exercise, Vol. 36, No. 6, pp. 1008-1016.

421 Mei, Q., Fernandez, J., Fu, W., Feng, N., \& Gu, Y. (2015). 'A comparative 422 biomechanical analysis of habitually unshod and shod runners based on a foot 423 morphological difference', Human movement science, Vol. 42, pp. 38-53.

424 Meyers, M. C. (2010). 'Incidence, mechanisms, and severity of game-related college 425 football injuries on fieldturf versus natural grass a 3-year prospective study', The 426 American journal of sports medicine, Vol. 38, No. 4, pp. 687-697.

427 Morio, C., Lake, M. J., Gueguen, N., Rao, G., \& Baly, L. (2009). 'The influence of 428 footwear on foot motion during walking and running', Journal of biomechanics, Vol. 429 42, No. 13, pp. 2081-2088.

430 Müller, C., Sterzing, T., Lange, J., \& Milani, T. L. (2010). 'Comprehensive evaluation 431 of player-surface interaction on artificial soccer turf', Sports Biomechanics, Vol. 9, No. 432 3, pp. 193-205.

433 Müller, C., Sterzing, T., \& Milani, T. (2009). 'Stud length and stud geometry of soccer 434 boots influence running performance on third generation artificial turf', In ISBS435 Conference Proceedings Archive, Vol. 1, No. 1.

436 Nigg, B. M., \& Segesser, B. (1988). 'The influence of playing surfaces on the load on 437 the locomotor system and on football and tennis injuries', Sports Medicine, Vol. 5, No. 438 6, pp. 375-385.

439 Schrier, N. M., Wannop, J. W., Lewinson, R. T., Worobets, J., \& Stefanyshyn, D. (2014). 440 'Shoe traction and surface compliance affect performance of soccer-related 441 movements', Footwear Science, Vol. 6, No. 2, pp. 69-80.

442 Smith, N., Dyson, R., \& Janaway, L. (2004). 'Ground reaction force measures when 443 running in soccer boots and soccer training shoes on a natural turf surface', Sports 444 Engineering, Vol. 7, No. 3, pp. 159-167. 
445 Sterzing, T., Müller, C., Hennig, E. M., \& Milani, T. L. (2009). 'Actual and perceived 446 running performance in soccer shoes: A series of eight studies', Footwear Science, Vol. 447 1, No. 1, pp. 5-17.

448 Torg, J. S. (1982). 'Athletic footwear and orthotic appliances', Clinics in sports 449 medicine, Vol. 1, No. 1, pp. 157-175.

450 Torg, J. S., \& Quedenfeld, T. (1971). 'Effect of shoe type and cleat length on incidence 451 and severity of knee injuries among high school football players', Research Quarterly. 452 American Association for Health, Physical Education and Recreation, Vol. 42, No. 2, 453 pp. 203-211. 